\title{
EVIDENCE-BASED PRACTICE IN SPEECH- LANGUAGE PATHOLOGY: SCALING UP
}

Laura M. Justice

The Ohio State University, Columbus, Ohio, United States

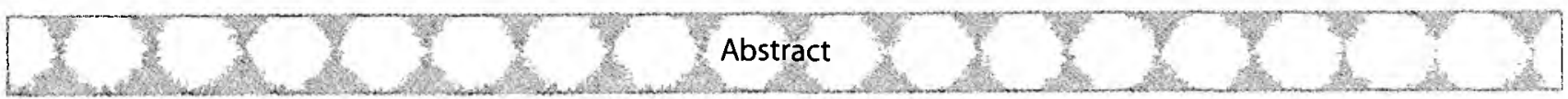

Evidence-based practice is a process to which clinical professionals adhere when making decisions concerning the assessment or treatment of a given condition. Within the field of speech-language pathology, it is increasingly advocated as best practice. As our profession seeks to transform itself from one that is primarily craft-based to one that relies on evidence-based processes, it must develop and implement a series of structures that will foster this transformation. This article describes three specific structures that are increasingly available within the field of speech-language pathology in the United States to guide transformation of the profession: systematicreviews and meta-analyses, treatment studies, and clearinghouses. Without these structural supports, it is unlikely that evidence-basedpracticecan bescaled up ina way that has positive impacts on practice.

\section{Keywords: evidence-based practice, systematic review, meta-analysis.}

$\mathrm{E}$ vidence-based practice is a process to which clinical professionals adhere when making decisions concerning the assessment or treatment of a given condition. This process involves careful consideration and integration of various types of evidence so that the most effective solution can be identified; these types of evidence include, minimally: (1) clinical expertise, (2) patient values and perspectives, and (3) best available scientific evidence (Sackett, Rosenberg, Gray, Haynes, \& Richardson, 1996; Sackett, Straus, Richardson, Rosenberg, \& Haynes, 2000). Evidence-based practice is recommended for use not only by speech-language pathologists, but also those involved with clinical decision-making in medicine (called evidencebased medicine; Evidence-Based Medicine Working Group, 1992), nursing (Porter-O'Grady, 2007), psychology (Spring, 2007), physical therapy (Cibulka \& Aslin, 2001), and special education (Cook \& Shirmer, 2006), among others. Regardless of one's discipline and, by consequence the nature and impact of the decisions to be made, the process of evidencebased practice is largely identical regardless of whether one is selecting a treatment regiment for high blood pressure, for clinical depression, for stuttering, or for reading disability. As members of the speech-language pathology community, it can be particularly insightful to examine the structures being put into place in other professions - medicine and education, for instance - as we transform our profession towards one that is evidence-based.

If we look to the larger literature on evidence-based practice, it is evident that all professions seeking transformation from craft-based to evidence-based clinical decision-making models are in the process of designing and implementing complex types of structures to not only ease this transformation but to make it even possible in the first place; some professions are much further along than others. By structures, I am referring to tangible items and tools that must be developed to allow a profession to become more embedded in evidence. These structures include, for instance, providing guidelines to clinicians as to how to formulate well-built clinical questions (Schlosser, Koul, \& Costello, 2007), developing consensus statements regarding how much and what type of evidence is needed for a treatment to be "empirically validated" (Gersten, Fuchs, Compton, Coyne, Greenwood, \& Innocenti, 2005), and articulating the sequenced steps that clinicians must follow so that they might conduct their own critical appraisals of the scientific literature (e.g., Fey \& Justice, 2006; Justice \& Snell, 2007). Within the field of speech-language pathology, these and many other structures necessary for the successful transformation of a profession to one that is evidence-based are in the process of being developed and have not, to any large extent, yet been taken to scale. Nonetheless, all signs point to the scaling up of evidence-based practice in the near future given that many relevant structures are being put into place.

Evidence-Based Practice in the United States: Structures Promoting Scalability

In this article, I discuss three specific structures that are increasingly available within the field of speech-language pathology in the United States: systematic reviews and meta-analyses, treatment studies, and clearinghouses. These three structures are, in my opinion, necessary tools for clinicians to engage in evidence-based practice and for a field to successfully transform itself to one that is evidence-based; their increasing availability provide evidence of the scaling up of evidence-based practice.

Systematic Reviews and Meta-analyses

Historically, speech-language pathologists in the United States have used practice guidelines (also called clinical guidelines) to help them answer pressing clinical questions. Practice guidelines are statements developed by teams of experts to guide practitioners in how to make decisions regarding specific circumstance (Field \& Lohr, 1990). Although they may be developed through a systematic process, practice guidelines do not typically involve a comprehensive review of the literature on a specific topic nor a critical analysis of available statistical data; they may, as a result, offer flawed interpretations of the literature that represent the biases of

Author Contact: Laura M. Justice, 356 Arps Hall,

1945 NHigh Street, The Obio State University,

Columbus OH 43210, United States

E-mail: justice.57@osu.edu 
those experts who are involved in generating the guidelines (Woolf, Grol, Hutchinson, Eccles, \& Grimshaw, 1999). In the field of medicine, experts express concerns that clinicians' use of practice guidelines can result in use of "ineffective, harmful, or wasteful interventions" (Woolf et al., 1999, p. 329).

As medicine and other professions, like speech-language pathology, seek to take evidence-based practice to scale, we see increased utilization of alternatives to practice guidelines - the systematic review and the meta-analysis - that offer a more systematic and potentially less biased approach towards synthesizing available research literature for the clinician. A systematic review is a scientific investigation of the available literature on a given topic. The review is systematic because the individual(s) completing the review adheres to a rigorous and preplanned process for identifying potential research articles for inclusion, appraising these articles to identify key findings, and for synthesizing findings across the identified body of work. A qualitative systematic review does not involve statistical analysis of the research findings aggregated across studies, whereas a quantitative systematic review - also called a meta-analysis - is a type of quantitative research design that involves statistically examining the aggregated results of a systematic review to determine the average level of effects attributable to a specific independent variable. The independent variable may involve treatment (e.g., average effects attributable to receiving specific types of treatment), measurement (e.g., average diagnostic accuracy of specific types of tests), and general aspects of development or disability (e.g., average concurrent or predictive association between two aspects of development, such as reading skill and intelligence or language ability and history of otitis media).Typically, a meta-analysis reports average effect sizes associated with a specific treatment or measure that is created by combining and then averaging data provided in each study in a set. An effect size is, essentially, the strength of an effect as represented in standard deviation units, typically reported using Cohen's $d$ for estimating differences between groups (e.g., for analyses of variance), or percentage of variance accounted for, reported using $r^{2}$ for correlational data. There are guidelines available in the literature, the most commonly used being those of Cohen (1988), that discuss how to interpret effect size estimates so that one knows if an average effect reported in a meta-analysis is small, medium, or large in size. Meta-analysis is most suitably applied when there are a reasonable number of studies available on a given topic, as too few studies can bias the results of a meta-analysis in both positive and negative directions.

To successfully engage in evidence-based practice, clinicians must have access to systematically conducted, valid systematic reviews of the accumulated literature to date. Qualitative systematic reviews can be particularly helpful for clinicians to understand what is known about a particular area of inquiry. For instance, Coelho, DeRuyter, and Stein (1996) provided a useful synthesis of efficacious treatment approaches for cognitive-communication impairments of adults secondary to traumatic brain injury. This article summarized the results of various approaches to treating this condition, although it did not statistically compare the average effects associated with any one treatment approach (e.g., mnemonic training) with that of other treatment approaches (visual imagery, executive strategy training), nor did it provide a summary of the average strength of effects associated with a specific training. It may be that one approach has very strong effects compared to other approaches, but the qualitative systematic review does not involve this type of analysis and therefore such interpretations are not possible. A unique strength of the meta-analysis is in the statistical combining of data across multiple studies and the resulting effect size estimates.

For professions that are seeking transformation towards being evidence-based, an important recent event is the shift towards generation of evidence-based systematic reviews and evidence-based clinical guidelines as replacements for traditional practice guidelines. These are similar to traditional practice guidelines in that they attempt to offer clinicians useable knowledge regarding a particular clinical problem, but they are generated through a much more systematic process than occurs with practice guidelines. The American Speech-Language-Hearing Association, in response to recommendations of the Joint Coordinating Committee on Evidence-Based Practice (American Speech-LanguageHearing Association, 2005), has shifted from generating practice guidelines to evidence-based systematic reviews and is in the process of accepting nominations for topics to address. The first evidence-based systematic review has undergone public comments and will be published in the near future; it examines the accumulated literature on the efficacy of constraint-induced language intervention for use in aphasia rehabilitation. The Academy of Neurologic Communication Disorders and Sciences (2001) also has embarked on developing evidence-based practice guidelines relevant to management of communication disorders in neurologically impaired individuals, to include traumatic brain injury, dementia, and aphasia, among others.

In addition to these initiatives at the national level, it is also relevant to note that several meta-analyses have been produced in recent years that greatly benefit clinicians' engagement in evidence-based practice. The results of metaanalyses permit the speech-language pathologist to make more informed decisions about the benefits that can reasonably be expected from a particular type of treatment. In the area of treatment, meta-analyses have studied general treatment effects for aphasia (Robey, 1998), child language disorders (Law, Garrett, \& Nye, 2004), communication problems associated with autism (Goldstein, 2002), fluency disorders (Andrews, Guitar, \& Howie, 1980), and attention problems associated with traumatic brain injury (Park \&Ingles, 2001), to name several. More specific aspects of treatment have also been explored, such as the average effects associated with particular treatment approaches (e.g., intratympanic gentamicin for Menière's Disease; Cohen-Kerem et al., 2004; behavioral treatments for stuttering; Herder, Howard, Nye, \& Vanryckeghem, 2006) or treatment contexts (e.g., pullout for inclusive models of language intervention; McGinty \& Justice, 2006). Table 1 lists several meta-analyses that are likely to be of interest to clinicians.

Meta-analyses are useful not only for estimating the effects of specific approaches to treatment, they are also quite important for demonstrating to the field where there are 
serious gaps in our knowledge. For instance, McGinty and Justice (2006) conducted a meta-analysis of outcomes attributable to various treatment contexts (e.g., classroombased, pull-out) for children with language disorders; they identified only three studies to date that have explicitly addressed this issue. As this example shows, as the field of speech-language pathology scales up evidence-based practice within the clinical realm, speech-language researchers must also ensure that the kinds of studies they are conducting produce useable knowledge that contributes to timely and pressing issues within clinical practice.

\section{Treatment Studies}

Speech-language pathologists who engage in evidencebased practice will turn not only to meta-analyses for guidance in decision-making but also to individual treatment studies. As noted earlier, a meta-analysis is really only useful when there are enough studies in a given area that aggregation of findings is possible. However, in many areas of practice there are far too few studies available on a given topic for a meta-analysis to be useful. For instance, the clinician who works with an adolescent who stutters and wants to treat the child's anxiety and embarrassment about speaking publicly will find no meta-analysis available on this topic (Yaruss \& Pelczarski, 2007). The clinician will then have to look towards individual treatment studies and examine these for guidance on a particular approach that appears to be efficacious.

While this seems straightforward, the field of speechlanguage pathology is plagued by a paucity of treatment studies. One recent study of group-design treatment studies published in three flagship American journals in speechlanguage pathology (Language, Speech, and Hearing Services in Schools; American Journal of Speech-Language Patbology; Journal of Speech, Language, and Hearing Research) found that only 52 such studies were published over a 10 -year period - averaging about 5 studies per year (Justice, Nye, Schwarz, McGinty, \& Rivera, 2008). Given that these studies address a broad range of treatment foci of relevance to speech-language pathology (e.g., fluency, voice, language, speech, literacy), it is clear that clinicians' access to treatment research is inadequate for meeting the broad range of clinical questions they encounter in everyday practice. As noted by members of the American Speech-Language-Hearing Association, a consequence of the field's transformation to evidence-based practice is the urgent need for research that addresses pressing clinical questions (American Speech-Language-Hearing Association, 2005).

Some evidence suggests that the generally limited production rate of treatment research is on the brink of change, and this is largely in response to shifts in the funding streams that support empirical research in speech-language pathology. The Institute of Education Sciences, which funds the majority of educational research in the United States, has dramatically shifted its funding priorities in the last five years to emphasize the production of more useable knowledge. As a result, funds provided to researchers who study the efficacy and effectiveness of specific interventions and treatments using randomized controlled trial (RCT) research designs have greatly increased. Many of these studies are of direct relevance to speech-language pathologists, such as studies of the efficacy of various language curricula for children at-risk for academic difficulties (Justice, Mashburn, Pence, \& Wiggins, 2008). The National Institutes of Health - and particularly the Institute that funds a great deal of research relevant to speech-language pathologists, the National Institute on Deafness and Other Communication Disorders (NIDCD) - has recently reported its intent to prioritize funding for "patient-oriented research" over less clinically-relevant basic research. One particular funding mechanism available through NIDCD prioritizes treatment research through its emphasis on funding research that "translates basic research findings into clinical tools" (NIDCD, 2007). Types of research activities supported through this funding mechanism include: (a) dosage studies, (b) intervention development studies, and (c) studies of prevention programs. In light of relatively stagnant levels of funding for social and behavioral research within the United States and the increasingly competitive nature of research funding, it is likely that we will see more speech-language researchers shift their research towards more treatment-oriented work, thereby fostering an increase in the number of treatment study publications. Indeed, members of the American Speech-Language-Hearing Association (2005) have specifically recommended an increase in the conduct of randomized controlled trials by researchers in speech-language pathology.

An important issue related to treatment studies and their relevance to clinicians' engagement in evidence-based practice regards the quality and quantity of studies available on a given topic. The quality of an empirical study, particularly those investigating treatments, largely concerns its internal validity and its external validity. Study methodologies that promote internal validity (e.g., randomization of patients, blinding of assessors) are what allow researchers to make strong causal statements regarding the manipulated independent variable (e.g., Treatment X) and a specific dependent variable (e.g., language comprehension). Study methodologies that promote external validity (e.g., random selection from a population) are what allow researchers to make strong statements regarding the generalization of findings from their sample to a larger population. Not all studies are done well (Justice et al., 2008) and those that are of poor quality can lead the clinician engaging in evidencebased practice to make undesirable treatment recommendations. The quantity of studies available on a given topic is an additional issue of relevance to evidence-based practice. The clinician's access to one study showing a positive effect for a given treatment should not be nearly so influential to his or her decision-making as having access to five studies that show consistently positive treatment effects. Knowledge is created through the accumulation of evidence and our practices should change only when there is a preponderance of compelling high quality evidence.

An important structure that has yet to be developed in the field of speech-language pathology in the United States is explicit guidance regarding how many treatment studies are needed for a given treatment to be considered "empirically validated." At the present, a speech-language pathologist may consider a specific treatment to be "empirically validated" or scientifically based on the basis of only a single study of any design reporting positive effects of that treat- 
Table 1.

Examples of meta-analyses on clinically relevant topics in speecb-language patbology

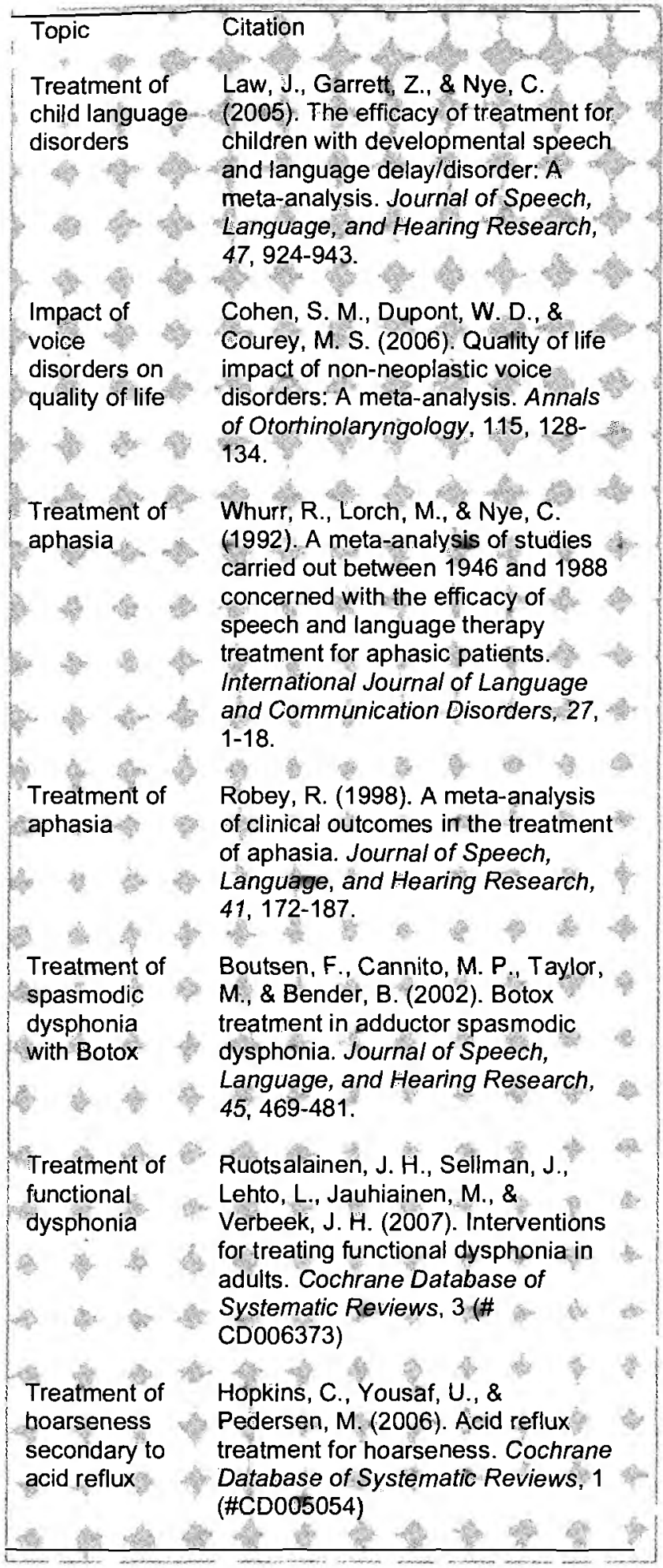

ment. This is problematic in a number of ways, the least being that the authors of a study may readily argue positive treatment effects even when the study design does not permit strong causal claims or there was a fatal flaw in the design. Other fields have set minimal standards regarding the strength of evidence needed - in terms of both quantity and quality of treatment studies - for a practice to be empirically validated (e.g., Lonigan, Elber, \& Johnson, 1998). However, the field of speech-language pathology has yet to develop this important structure which, in my opinion, is absolutely necessary for clinicians to be discerning consumers of the accumulating empirical literature and to successfully engage in evidence-based practice.

\section{Clearinghouses}

Speech-language pathologists are busy. In an era of limited financial resources, clinicians are constantly being asked to do more for less. As a result, it is unreasonable to expect speech-language pathologists to conduct a thorough highquality review of the empirical literature for every clinical issue that they must address. Not only do clinicians lack the time to engage in such activities, but they may not have access to the physical resources to do so (e.g., electronic journals, databases) and they may not have the skills necessary to conduct what amounts to an informal meta-analysis of the accumulated research papers available on a given topic. Consequently, an absolutely critical resource necessary for the scaling up of evidence-based practice is the development of clearinghouses that allow clinicians to study condensed and useable descriptions of the accumulated scientific literature on a specific topic. Currently, there are two types of clearinghouses that provide interpretations of the empirical literature: (1) clearinghouses that publish systematic reviews and meta-analyses that are commissioned or volunteered to address specific topics, and (2) clearinghouses that provide links to resources on evidence-based practice, such as lists of studies on a given topic and links to practice guidelines on specific topics. Examples of this latter type of clearinghouse include the American Speech-Language-Hearing Association's Compendium of EBP Guidelines and Systematic Reviews (www.asha.org), and The National Guideline Clearinghouse (www.guideline.gov), an initiative of the United States Department of Health and Human Services' Agency for Healthcare and Quality. Of the two types of clearinghouses, the former is the decidedly more useful to the clinician engaged in evidence-based practice, as it provides access to systematic reviews and meta-analyses that summarize a body of work for the busy clinician. These reviews and meta-analyses are typically prepared by experts in the field and they must follow specific guidelines regarding how to identify studies on a specific topic, how to analyze these, and how to report findings.

Likely the two most well known clearinghouses are that of the Cochrane Collaboration (www.cochrane.org) and the Campbell Collaboration (www.campbellcollaboration.org). Both are international non-profit organizations that exist specifically to develop systematic reviews of the available literature on treatment and assessment in the field of health and medicine (Cochrane) and social and behavioral sciences (Campbell). Not only do these organizations provide access to a large database of reviews on a range of clinically, relevant topics, but numerous tools are available to support one's developing knowledge of how to engage in evidence-based practice and how to conduct critical reviews of the scientific literature. A more recent addition is the What Works Clearinghouse (ies.ed.gov) of the United States Department of Education; this clearinghouse both commissions and disseminates systematic reviews of educationally-relevant in- 
Table 2.

Recent treatment studies on clinically relevant topics in speech-language patbology

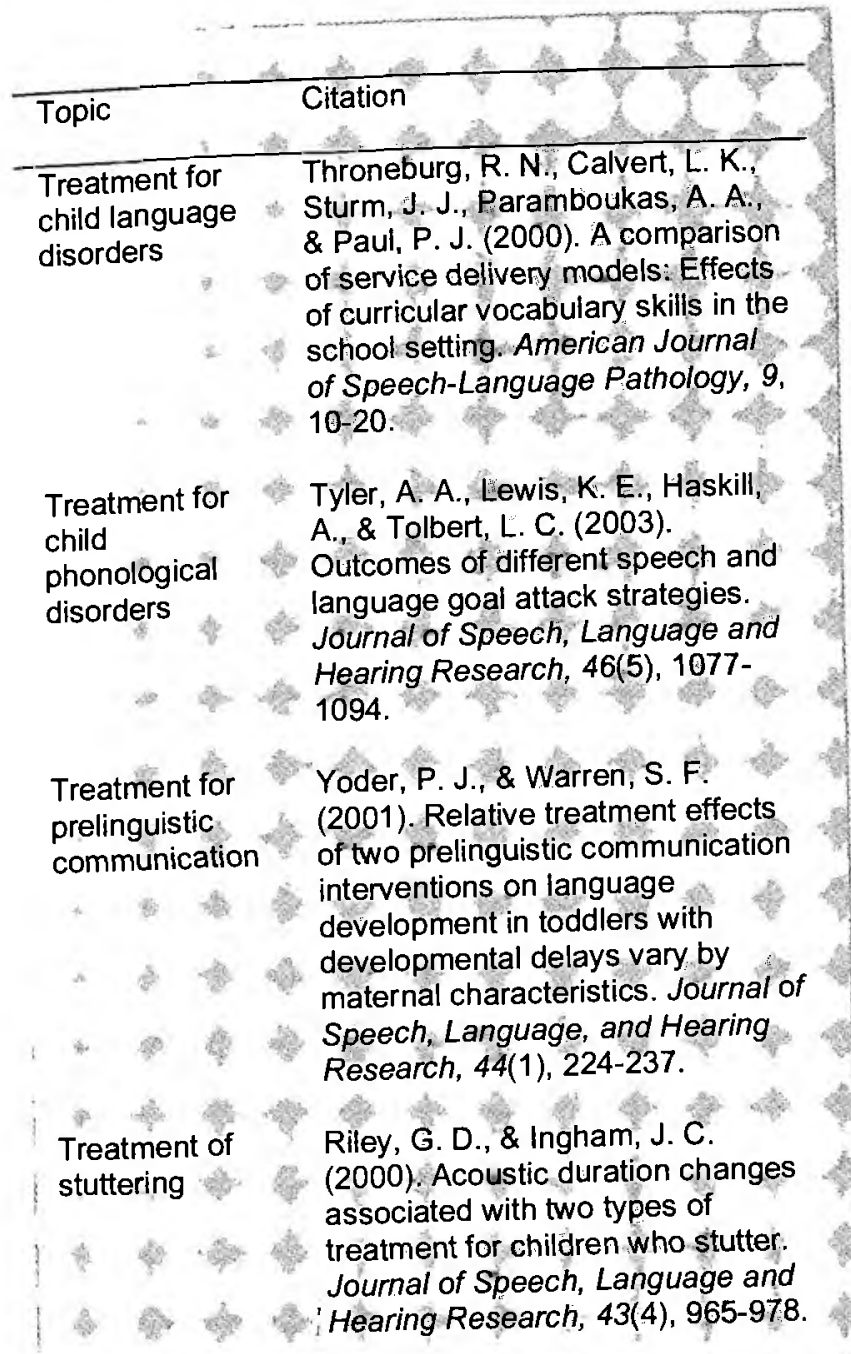
aphasia

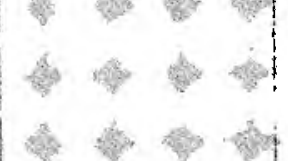

Treatment for dementia

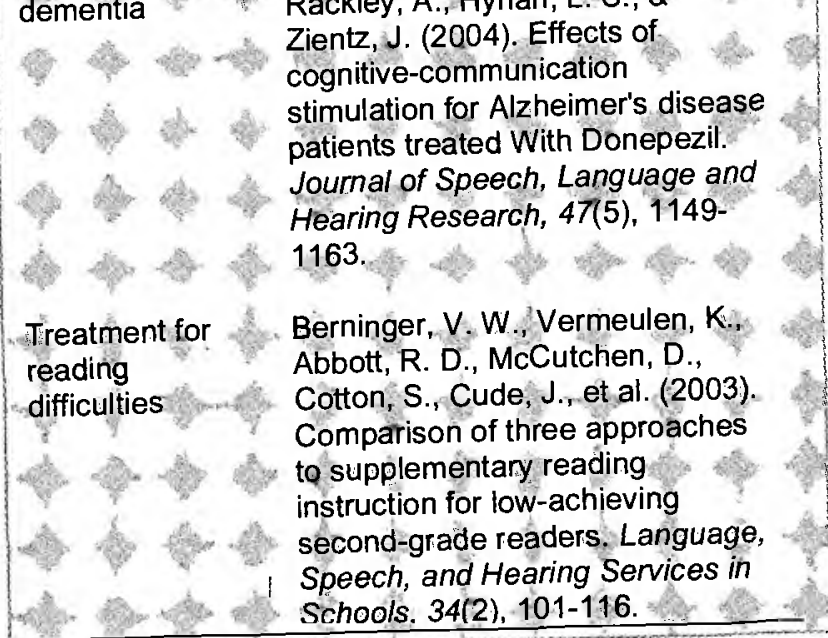

terventions on various topics (e.g., Phonological Awareness Training, Shared Book Reading) but also gives "ratings of effectiveness" to specific interventions that include positive effects, potentially positive effects, mixed effects, no discernable effects, and potentially negative effects; additionally, studies included in their reviews are also graded for the quality of the design (strong, weak).

Several other clearinghouses aside from Cochrane, Campbell, and What Works may also offer information of relevance to speech-language pathology. The California Evidence-Based Clearinghouse for Child Welfare (www.cachildwelfareclearinghouse.org) is organized similarly to that of the What Works Clearinghouse and provides commissioned reviews of topics related to child welfare. On the basis of the available evidence, specific interventions are rated for the strength of evidence (e.g., well-supported by scientific evidence, lacks adequate research evidence). Although many of the reviews available are not directly relevant to the speechlanguage pathologist, some may be informative to clinical practice, such as the reports in the topic areas addressing Youth Transitioning into Adulthood and Parent Training. The Coalition for Evidence-Based Policy offers summaries of well-conducted randomized controlled studies on a variety of topics through their Social Programs That Work clearinghouse (www.evidencebasedprograms.org). Recent reports describe effects associated with the Nurse-Family Partnership (a home visitation program) and the Abecedarian Preschool project (an early intervention program). The Center for Data-Driven Reform in Education offers summaries of scientific reviews in its Best Evidence Encyclopedia (www.bestevidence.org). Reviews concerning the use of technology to teach reading and approaches to promoting literacy in English Language Learners may be of interest to speech-language pathologists. The Promising Practices Network offers the Programs That Work Clearinghouse (www. promisingpractices.net), which offers summaries of efficacious programs relevant to intervention for and education of children; programs are organized into categories based on the apparent strength of evidence (e.g., proven programs, promising programs).

\section{Concluding Comments}

Evidence-based practice is a process to which speechlanguage pathologists may adhere when making decisions concerning the assessment or treatment of communication disorders. The clinician who engages in evidence-based practices carefully considers and integrates various types of evidence to arrive at the most effective solution to a specific clinical question. The types of evidence examined include, at the least: (1) clinical expertise, (2) patient values and perspectives, and (3) best available scientific evidence (Sackett et al., 1996, 2000). While the former two types of evidence are readily available to the clinician, accessing the best available scientific evidence may take a great deal of work and presents one of the largest challenges the clinician faces who seeks to engage in evidence-based practice. Consequently, structures must be put into place that enable the speech-language pathologist to readily access and synthesize the relevant empirical literature and to consider its implications for a given clinical question. These structures are what will permit the scalability of evidence-based practice, and in- 
clude, in part, systematic reviews and meta-analyses, treatment studies, and clearinghouses that together provide useable reports, syntheses, and interpretations of the scientific literature. Without these structural supports, it is unlikely that evidence-based practice can be scaled up in a way that has positive impacts on practice. Future efforts regarding the promotion of evidence-based practice must focus not only on training clinical professionals how to engage successfully in this practice, but also the building of those structures necessary for the field to successfully transition from relying on craft to one that relies largely on evidence.

\section{References}

Academy of Neurologic Communication Disorders and Sciences (2001). Evidence based practice guidelines for the management of communication disorders in neurologically impaired individuals. Retrieved June 15, 2008 from http://www.ancds.org/practice. shtml.

American Speech-Language-Hearing Association. (2005). Evidence-Based Practice in Communication Disorders [Position Statement]. Retrieved from http://www.asha.org/policy.

Andrews, G., Guitar, B., \& Howie, P. (1980). Meta-analysis of the effects of stuttering treatment. Journal of Speech and Hearing Disorders, 45, 287-307.

Cook, B. G., \& Schirmer, B. R. (2006). What is special about special education? Examining the role of evidence-based practices. Austin: PRO-ED.

Cibulka, M. \& Aslin, K. (2001). How to use evidence based practice to distinguish between three different patients with low back pain. Journal of Ortbopedic and Sports Physical Therapy, 31, 678-695.

Coelho, DeRuyter \& Stein (1996). Cognitive-communicative disorders resulting from traumatic brain injury in adults. Journal of Speech, Language and Hearing Research, 39, 5-17.

Cohen, J. (1988). Statistical power analysis for the bebavioral sciences (2nd ed.). Hillsdale: Lawrence Earlbaum Associates.

Cohen-Kerem, R., Kisilevsky, V., Einarson, T., Kozer, E., Koren, G., \& Rutka, J. (2004). Intratympanic gentamicin for Meniere's disease: A meta-analysis. The Laryngoscope, 114, 2085-2091.

Evidence-Based Medicine Working Group (1992). Evidencebased medicine: a new approach to teaching the practice of medicine. Journal of the American Medical Association, 268, 2420-2425.

Fey, M, \& Justice, L. M. (2006). Evidence-based decision-making in communication intervention. In R. Paul and P. Cascella (Ed.), Introduction to clinical methods in communication disorders (2 $2^{\text {nd }}$ ed.). Baltimore: Paul Brookes.

Field, M. J., \& Lohr, K. N. (Eds.). (1990) Clinical practice guidelines: directions for a new program. Washington: National Academy Press.

Gersten, R., Fuchs, L., Compton, D., Coyne, M., Greenwood, C., \& Innocenti, M. (2005). Quality indicators for group experimental and quasi-experimental research in special education. Exceptional Cbildren, 71, 149-164.

Goldstein, H. (2002). Communication intervention for children with autism: A review of treatment efficacy. Journal of Autism and Developmental Disorders, 32, 5, 373-396.

Herder, C., Howard, C., Nye, C., \& Vanryckeghem, M. (2006). Effectiveness of behavioral stuttering treatment: A systemic re- view and meta-analysis. Contemporary Issues in Communication Sciences and Disorders Journal, 33, 61-73.

Justice, L. M., Mashburn, A., Pence, K., \&Wiggins, A. (2008). Experimental evaluation of a comprehensive language-rich curriculum in at-risk preschools. Journal of Speech, Language, and Hearing Research, 51, 1-19.

Justice, Nye, Schwarz, McGinty \& Rivera (2008). Methodological quality of intervention research in speech-language pathology: Analysis of 10 years of group-design studies. Evidence-Based Communication Assessment and Intervention, 2, 46-59.

Justice, L. M., \& Snell, M. (2007). Illustration of a three-step process for identifying the level and quality of empirical support for manualized treatments. Evidence-Based Communication Assessment and Intervention, 1, 37-47.

Law, J., Garrett, Z., \& Nye, C. (2004). The efficacy of treatment for children with developmental speech and language delay/disorder: A meta-analysis. Journal of Speech, Language, and Hearing Research, 47, 924-94.

Lonigan, C., Elber, J., \& Johnson, S. (1998). Empirically supported interventions for children: An overview. Journal of Clinical Child Psychology, 27, 138-145.

McGinty, A. S., \& Justice, L. M. (2006). Classroom-based versus pullout speech-language intervention: A review of the experimental evidence. EBP Briefs, 1, 1, 1-25.

National Institute on Deafness and Other Communication Disorders (2007). NIDCD Research Grants for Translating Basic Research into Clinical Tools for Human Health (R01). Retrieved June 10, 2008 from http://grants.nih.gov/grants/guide/pafiles/PAR-08-017.html.

Park, N. W., \& Ingles, J. L. (2001). Effectiveness of attention rehabilitation after an acquired brain injury: A meta-analysis. Neuropsychology, 15, 2, 199-210.

Porter-O'Grady T. (2007). Push parameters forward using evidence-based approaches. Nursing Management, 38, 6, 58-61.

Robey, R. (1998). A meta-analysis of clinical outcomes in the treatment of aphasia. Journal of Speech, Language, and Hearing Research, 41, 172-187.

Sackett, D. L., Rosenberg, W. M., Gray, J. A., Haynes, R. B., \& Richardson, W. S. (1996). Evidence based medicine: what it is and what it isn't: It's about integrating individual clinical expertise and the best external evidence. British Medical Journal, 312, 71-72.

Sackett, D., Straus, S., Richardson, W., Rosenberg, W. \& Haynes, R. (2000). Evidence-Based Medicine: bow to practise and teach $E B M\left(2^{\text {nd }}\right.$ ed). London: Churchill Livingstone.

Schlosser, R., Koul, R., \& Costello, J. (2007). Asking well-built questions for evidence-based practice in augmentative and alternative communication. Journal of Communication Disorders, 40,3, 225-238.

Spring, B. (2007). Evidence-based practice in clinical psychology: What it is, why it matters; what you need to know. Journal of Clinical Psychology, 63, 611-631.

Woolf, S. H., Grol, R., Hutchinson, A., Eccles, M., \& Grimshaw, J. (1999). Clinical guidelines: Potential benefits, limitations, and harms of clinical guidelines. British Medical Journal, 318, 728730.

Yaruss, S., \& Pelczarski, K. (2008). Evidence-based practice for school-age stuttering: Balancing existing research with clinical practice. $E B P$ Briefs, 2, 4, 1-8. 